\title{
Fruit-related terms and images on food packages and advertisements affect children's perceptions of foods' fruit content
}

\author{
Rebecca Heller ${ }^{1}$, Jennifer Martin-Biggers ${ }^{2, *}$, Amanda Berhaupt-Glickstein ${ }^{2}$, \\ Virginia Quick ${ }^{3}$ and Carol Byrd-Bredbenner ${ }^{2}$ \\ ${ }^{1}$ St. Joseph's Healthcare System, Wayne, N, USA: ${ }^{2}$ Department of Nutritional Sciences, Rutgers University, 211 Davison \\ Hall, New Brunswick, NJ 08901, USA: ${ }^{3}$ Department of Health Sciences, James Madison University, Harrisonburg, VA, USA
}

Submitted 8 July 2014: Final revision received 23 January 2015: Accepted 28 January 2015: First published online 8 April 2015

\begin{abstract}
Objective: To determine whether food label information and advertisements for foods containing no fruit cause children to have a false impression of the foods' fruit content. Design: In the food label condition, a trained researcher showed each child sixteen different food label photographs depicting front-of-food label packages that varied with regard to fruit content (i.e. real fruit $v$. sham fruit) and label elements. In the food advertisement condition, children viewed sixteen, $30 \mathrm{~s}$ television food advertisements with similar fruit content and label elements as in the food label condition. After viewing each food label and advertisement, children responded to the question 'Did they use fruit to make this?' with responses of yes, no or don't know.

Setting: Schools, day-care centres, after-school programmes and other community groups.

Subjects: Children aged 4-7 years

Results: In the food label condition, $\chi^{2}$ analysis of within fruit content variation differences indicated children ( $n 58$; mean age 4.2 years) were significantly more accurate in identifying real fruit foods as the label's informational load increased and were least accurate when neither a fruit name nor an image was on the label. Children ( $n$ 49; mean age 5.4 years) in the food advertisement condition were more likely to identify real fruit foods when advertisements had fruit images compared with when no image was included, while fruit images in advertisements for sham fruit foods significantly reduced accuracy of responses.

Conclusions: Findings suggest that labels and advertisements for sham fruit foods mislead children with regard to the food's real fruit content.
\end{abstract}

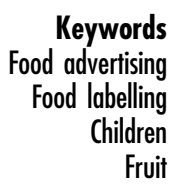

Content analyses have repeatedly shown that foods advertised during children's programming and prime-time hours tend to be high in energy and low in nutrients ${ }^{(1-4)}$. There also is concern regarding the truthfulness of nutritionrelated verbal claims and visual depictions in advertisements ${ }^{(5)}$. A content analysis of Saturday morning food advertisements broadcast on children's television during the last 15 years led the authors of the present paper to question whether some of the low-nutrient-density fruitflavoured candy and beverage advertisements, in particular, were creating an erroneous impression of the foods' actual fruit content ${ }^{(5,6)}$. For example, one advertisement seemed to visually imply a candy contained substantial amounts of fruit when the actual fruit content was extremely small and was in the form of fruit juice concentrate. $\dagger$

$†$ Fruit purée or juice concentrate contains approximately three to six times more sugar, respectively, than $100 \%$ fruit juice (Product specifications, Tropico-Industrial Fruit Division, 2004), thereby contributing substantially fewer nutrients and more energy per gram than real fruit.
Subsequent content analysis of the packages (retail container or wrapping) ${ }^{(7)}$ of the advertised fruit-flavoured foods revealed that pictures of fruit were commonly and prominently displayed ${ }^{(8)}$. Pictures on food labels help consumers efficiently evaluate a product's intrinsic organoleptic and health-related attributes ${ }^{(9,10)}$. The relative favourableness of the information conveyed by pictures also affects attitudes towards the food and purchase intentions $^{(11-13)}$. Thus, pictures of fruit on food packages that contain little or no fruit may create a false impression of the food and its health benefits ${ }^{(14,15)}$. In addition, names of foods containing little or no fruit may imply that fruit is a major ingredient (e.g. product names that include 'fruity', ‘juicy' or names of specific fruits $)^{(13,16)}$. Visual depictions of fruit and/or product names and descriptions may imbue products with a health halo that influences individuals' perceptions and food choices ${ }^{(8-11,13,14,17,18)}$.

According to communication theory, food labels and advertisements are communication channels used by food 
manufacturers to transmit (encode) messages to consumers who, in turn, receive and decode them to derive their meaning ${ }^{(19)}$. According to Habermas' Theory of Communicative Action, consensual understanding is reached when communications are free of distortion, coercion and ideology, and are truthful, sincere, comprehensible and legitimate $^{(14,20)}$. Content analyses suggest that some food advertisements and labels may not adhere to Habermasian standards ${ }^{(20)}$. That is, they appear deceptive; however, the question remains as to whether they actually deceive consumers and affect their behaviours ${ }^{(5,6,14)}$.

Deception analysis begins by first identifying expressed or implied claims made by advertisements, food names or packaging images. Expressed claims are made explicitly, whereas implied claims are impressions created by the textual and visual references and their relationship to each other. The second step is to determine consumers' beliefs about the food based on the advertisement, food name or packaging image claims. The third step is to determine whether advertising, food name or packaging images affect consumers' use of the product ${ }^{(21,22)}$. The content analyses available are very useful in providing the information needed to begin the process of deception analysis. However, little published work has assessed consumer perceptions of nutrition-related information in food advertisements ${ }^{(18,23-27)}$. There also is a dearth of studies examining consumer assumptions about foods' nutritional value based on their packaging and subsequent food selection decisions ${ }^{(9,28,29)}$. Thus, the purpose of the present study was to move beyond the first step of deception analysis to describe how consumers perceive the potentially deceptive components of food advertisements, product names and packaging images identified by researchers in content analyses and how these perceptions affect food choice. In specific, the purpose of the study was to determine whether food label information (i.e. food names and images) and advertisements for foods containing no fruit cause children to have a false impression of the foods' fruit content and, therefore, healthfulness. Children are an especially important consumer audience to study because their cognitive immaturity limits their ability to comprehend the 'selling intent' of advertisements ${ }^{(18,25,30-35)}$. Concomitantly, their underdeveloped abilities to exercise self-control to resist temptations, like snacks advertised on television or displayed in attractive packages on grocery shelves, makes it difficult for parents to say 'no' to their demands to purchase the item ${ }^{(36)}$. Thus, even young children can exert an important influence on family food purchases ${ }^{(18,25,30-34)}$.

\section{Methods}

The present research had two study conditions: food labels and food advertisements. Permission to conduct the study was secured from the authors' university Institutional Review Board prior to recruitment.

\section{Sample}

Children (aged 4-7 years) were recruited from schools, day-care centres, after-school programmes and other community groups. Data were collected from children who verbally assented to participate after their parents granted informed consent permission for them to participate in the study. Data collection continued until the sample quota of approximately fifty was reached in each condition.

\section{Procedure}

Each child participated in only one of the two study conditions. The data collection procedure for both study conditions was based on previous research ${ }^{(18,28,29,37)}$. In both conditions, a trained researcher and child sat side by side at a table in a distraction-free room. The table was pre-set with stimulus materials (i.e. a deck of food label photographs or a computer for showing recorded television food advertisements), which are described below. A research assistant was seated out of the child's line of site but near enough to accurately record the child's responses.

\section{Food label condition}

This condition was designed to determine how food label information (i.e. food name and images) affects children's perceptions of the foods' fruit content. The stimulus material in this condition was a deck of sixteen food label photographs, which were constructed based on previous research $^{(38)}$. In specific, each food label photograph depicted the front of a food package. The photographs were scaled to reflect the relative size of the food package in relation to all food packages in the deck. Each photograph was printed in colour on a sheet of $21.6 \mathrm{~cm} \times 27.9 \mathrm{~cm}$ $(8.5$ in $\times 11$ in) white card stock.

To control for familiarity, labels from foods unavailable in the study area (e.g. foods sold in other regions or retired foods not marketed during the child's lifetime) were used in the deck. As shown in Table 1, the foods varied with regard to fruit content and label elements thereby creating a two by four design. Fruit Content Variations were foods that contained either: (i) real fruit (e.g. fruit juice, fruit cocktail; fruit content $>90 \%$ by weight); or (ii) sham fruit (i.e. contained no real fruit, but contained artificial fruit flavours). Fruit content was verified by the ingredient labels on the foods. There were four Label Element Variations for both Fruit Content Variations. The Label Element Variations differed with regard to informational load. The Label Element Variations in ascending order of informational load were labels from foods that had: (i) neither a fruit-related name nor fruit image; (ii) a fruitrelated name but no fruit image; (iii) a fruit image but no fruit-related name; or (iv) both a fruit-related name and a fruit image. ('Fruit-related' was defined as having the word fruit(y), juice (juicy) and/or specific fruit name(s) in its name. Fruit images were photographs or drawings of whole fruit. An array of products, such as breakfast 
Table 1 Fruit content and label and advertising element variations

\begin{tabular}{lcc}
\hline $\begin{array}{l}\text { Fruit content variations/Label and } \\
\text { advertisement element variations }\end{array}$ & $\begin{array}{c}\text { Fruit name (verbal } \\
\text { fruit reference) })^{*}\end{array}$ & $\begin{array}{c}\text { Fruit } \\
\text { image† }\end{array}$ \\
\hline Real fruitł & Yes & No \\
Element variation A & No & Yes \\
Element variation B & Yes & Yes \\
Element variation C & No & No \\
Element variation D & & \\
Sham fruitt & Yes & No \\
Element variation A & No & Yes \\
Element variation B & Yes & Yes \\
Element variation C & No & No \\
Element variation D & &
\end{tabular}

*For the Food Label Condition, food name included the word fruit(y), juice (juicy) or specific fruit name(s). For the Food Advertising Condition, verbal fruit references used the word fruit(y), juice (juicy) or specific fruit name(s) in the food name or in describing the food.

†For both the Food Label and Food Advertising Conditions, images (i.e. drawings, photographs and/or video) of fruit were included.

‡Real fruit foods were composed primarily of fruit or $100 \%$ fruit juice (>90\% by weight); sham fruit foods contained no real fruit, but contain artificial fruit flavours. Possible score range $=0$ to 100 ; higher scores indicate greater accuracy with regard to whether fruit was used to make the product.

cereals, beverages and snacks, were included.) Each Fruit Content Variation had eight labels (two labels for each Label Element Variation), resulting in sixteen food photographs. A panel of five nutrition researchers unanimously agreed that the ingredient label met the criteria for the Food Content Variations and the food label photographs met the criteria for the Label Element Variations.

Data collection began with the researcher explaining that she would like the child to look at some pictures of foods. The researcher then held up the first photograph in the deck and asked the child, 'Did they use fruit to make [name of product]?' (The phrasing of the question was based on previous research ${ }^{(18)}$ and pilot testing outcomes.) The research assistant recorded the child's answers as 'yes' (fruit was used), 'no' (fruit was not used) or 'don't know'. Given the verbal capabilities of young children, answers given as head movements (nods, shakes) and/or pointing were confirmed by repeating the child's answer and getting confirmation as to its accuracy (e.g. 'You are nodding your head, does that mean that fruit was used to make the food?'). This same procedure was followed for all food label photographs in the deck. Prior to asking children about the sixteen photographs in the research deck, a practice session of three foods (e.g. fruit salad, macaroni and cheese, and chocolate sandwich cookies) was conducted to ascertain that children were able to differentiate between real fruit and sham fruit foods. Inability to categorize the practice set indicated a child's cognitive development was not yet sufficiently mature for the present study; thus data collection was terminated. For children who were able to successfully complete the practice session, the sequence in which the food label photographs were presented was randomized at each administration. All children, whether they could complete the data collection session or not, were thanked and rewarded with sheet of smiley face stickers.
Scores were computed by determining the percentage of correct answers for all items answered 'yes' or 'no' by the child (i.e. the number of foods correctly identified as containing or not containing fruit were summed and divided by the total number of items answered 'yes' or 'no'; 'don't know' answers were not included). Thus, scores could range from 0 to $100 \%$. Total scores and scores for each of the Label Element Variation were calculated. The three foods in the practice session were not included in the score.

\section{Food advertisement condition}

This condition was designed to determine how information in television food advertisements (i.e. images and verbal references) affects children's perceptions of foods' fruit content. Advertisements were approximately $30 \mathrm{~s}$ in length and were obtained from video recordings from previous research studies as well as from Internet sources. The advertised foods varied with regard to fruit content and advertising elements. The Fruit Content Variations were the same as those in the food label condition (see Table 1). Advertising Element Variations and informational load for the two Fruit Content Variations were similar to the food label condition, but adapted to account for differences in labels and television advertising. In specific, Advertising Element Variations were advertisements with: (i) neither verbal fruit references nor fruit images; (ii) verbal fruit references but no fruit images; (iii) fruit images but no verbal fruit reference; or (iv) both verbal fruit references and fruit images. An array of product categories was included for sham fruits; however, even after intensive, widespread searching and evaluation a majority of real fruit advertisements were juices. Each Fruit Content Variation had eight advertisements (two advertisements for each Advertising Element Variation), resulting in sixteen food advertisements. A panel of nutrition researchers reviewed the ingredient labels for each food and each advertisement; they unanimously agreed that the foods met the criteria for the Fruit Content Variations and Advertising Element Variations, respectively.

The procedure for this condition largely mirrored that of the food label condition. The researcher explained that she would like the child to look at some television advertisements. After each advertisement, the researcher stopped the presentation and asked the child, 'Did they use fruit to make this?' Procedures for recording the child's answers, calculating scores, practising before data collection and rewarding children were the same as those used in the food label condition. Additionally, the sequence of the advertisements was randomized at each administration.

\section{Data analysis}

Descriptive statistics were used to summarize the participants' age and gender. Means and standard deviations for each of the food label element and advertising element 
variation scores were calculated for both Fruit Content Variations. For both conditions, independent $t$ tests were calculated to determine whether each food label (or advertising) element variation scores differed significantly between the real fruit and sham. A $\chi^{2}$ analysis was used to examine whether food label (or advertising) element variations within each Fruit Content Variation differed. Statistical significance was set at $P \leq 0 \cdot 05$.

\section{Results}

\section{Food label condition}

Of the 106 children who began this condition, fifty-eight were sufficiently cognitively mature to complete it. Those who were unable to complete the condition were significantly younger than those who completed it (mean age $=4.2 v .4 .9$ years). The gender split for the completers and non-completers was similar with about half being male.

Independent $t$ tests indicated that mean values for real fruit and sham Fruit Content Variation scores differed significantly for each Label Element Variation (Table 2). The $\chi^{2}$ analysis of within Fruit Content Variation differences indicated children were significantly more accurate in identifying real fruit foods as the label's informational load increased. That is, foods made with fruit were more likely to be correctly identified as being made with fruit when the food label contained both a fruit name and fruit image. Accuracy rate decreased when the food label contained a fruit image but no fruit name or when there was a fruit name but no fruit image. Children were significantly least accurate when neither a fruit name nor image was on the label.

Comparisons of Label Element Variations for sham fruit foods were the inverse of those of real fruit foods. That is, correctly identifying sham fruit foods as not being made with fruit declined significantly as the label informational load increased. Scores from lowest to highest for sham fruit food labels had these characteristics: both a fruit name and image, fruit image but no fruit name, fruit name but no image, and neither a fruit name nor image.

\section{Food advertisement condition}

Of the sixty-five children who began this condition, fortynine were sufficiently cognitively mature to complete it. Those who were unable to complete the condition were significantly younger than those who completed it (mean age $=5 \cdot 4 v \cdot 6 \cdot 2$ years). The gender split for the completers and non-completers was similar with about two-thirds being male.

Independent $t$ tests between the real and sham Fruit Content Variation scores indicated that participants differed significantly on all four Advertising Element Variations (Table 3). Overall, children more accurately identified real

Table 2 Accuracy of young children's perceptions of foods' fruit content based on foods' front-of-package label elements ( $n$ 58)

\begin{tabular}{|c|c|c|c|c|c|}
\hline \multirow[b]{2}{*}{ Food front-of-package label elements } & \multicolumn{2}{|c|}{ Foods containing real fruit* } & \multicolumn{2}{|c|}{ Foods containing sham fruit* } & \multirow[b]{2}{*}{$P \dagger$} \\
\hline & Mean & SD & Mean & SD & \\
\hline Neither fruit nameł nor fruit image§ & $27^{a}$ & 36 & $55^{a}$ & 41 & 0.0033 \\
\hline Fruit name but no fruit image & $70^{\mathrm{b}}$ & 39 & $46^{\mathrm{b}}$ & 47 & 0.046 \\
\hline Fruit image but no fruit name & $75^{c}$ & 37 & $24^{\mathrm{c}}$ & 39 & $<0.0001$ \\
\hline Both fruit name and fruit image & $81^{d}$ & 34 & $11^{d}$ & 23 & $<0.0001$ \\
\hline All elements combined (total score) & 64 & 28 & 34 & 30 & 0.0001 \\
\hline
\end{tabular}

${ }^{a, b, c, d}$ Mean values within a column with unlike superscript letters were significantly different $(P<0.01)$ as determined by $x^{2}$ test.

${ }^{*}$ Real fruit foods were composed primarily of fruit or $100 \%$ fruit juice ( $>90 \%$ by weight); sham fruit foods contained no real fruit, but contain artificial fruit flavours. Possible score range $=0$ to 100 ; higher scores indicate greater accuracy with regard to whether fruit was used to make the product.

†Probability of significant differences between real fruit and sham fruit foods as determined by independent $t$ test.

fFood name included the word fruit(y), juice (juicy) or specific fruit name(s).

$\S$ Label images included drawing(s) and/or photograph(s) of fruit.

Table 3 Accuracy of young children's perceptions of foods' fruit content based on food advertising elements ( $n$ 49)

\begin{tabular}{|c|c|c|c|c|c|}
\hline \multirow[b]{2}{*}{ Food advertising elements } & \multicolumn{2}{|c|}{ Foods containing real fruit* } & \multicolumn{2}{|c|}{ Foods containing sham fruit* } & \multirow[b]{2}{*}{$P \dagger$} \\
\hline & Mean & SD & Mean & SD & \\
\hline Neither fruit nameł nor fruit image§ & $81^{a}$ & 34 & $42^{a}$ & 41 & $<0.0001$ \\
\hline Fruit name but no fruit image & $72^{b}$ & 41 & $42^{\mathrm{a}}$ & 40 & 0.0017 \\
\hline Fruit image but no fruit name & $89^{\mathrm{c}}$ & 26 & $28^{\mathrm{b}}$ & 32 & $<0.0001$ \\
\hline Both fruit name and fruit image & $90^{\mathrm{C}}$ & 23 & $17^{\mathrm{C}}$ & 30 & $<0.0001$ \\
\hline All elements combined (total score) & 83 & 21 & 33 & 27 & $<0.0001$ \\
\hline
\end{tabular}

a,b,c Mean values within a column with unlike superscript letters were significantly different $(P<0.01)$ as determined by $\chi^{2}$ test.

${ }^{*}$ Real fruit foods were composed primarily of fruit or $100 \%$ fruit juice ( $>90 \%$ by weight); sham fruit foods contained no real fruit, but contain artificial fruit flavours.

Possible score range $=0$ to 100; higher scores indicate greater accuracy with regard to whether fruit was used to make the product.

†Probability of significant differences between real fruit and sham fruit foods as determined by two-sample unequal-variance $t$ test.

$\ddagger$ Verbal reference included the word fruit(y), juice (juicy) or specific fruit name(s).

$\S$ Advertisement included one or more images (i.e. drawings, photographs and/or video) of fruit. 
fruit foods as containing fruit than identifying sham fruit foods as not containing fruit. Real fruit foods with advertisements that incorporated fruit images tended to be significantly more likely to be identified as containing fruit than when no image was included. In contrast, the presence of fruit images in advertisements for sham fruit foods significantly reduced accuracy of responses. When both a fruit verbal reference and image (the highest information load) were present, the mean score for identifying sham fruit foods as not containing fruit was significantly lower than for all other Advertising Element Variations.

\section{Discussion}

Findings from the present study suggest that when there are fruit images and fruit-related names for products, children perceive them as containing fruit, regardless of whether or not they actually contain fruit. In the food label condition, as the informational load on food labels increased, the accuracy of identifying real fruit foods as containing fruit also increased. Conversely, the accuracy of identifying sham fruit foods as not being made with fruit decreased as informational load on labels increased. That is, when there was neither a fruit name nor fruit image present on the package, children received no fruit-related cues and were more likely to correctly identify sham fruit foods as not being made with fruit. In both the food label and food advertising conditions, as the informational load increased, children were increasingly misled that sham fruit foods contained real fruit.

In both conditions, the presence of fruit images alone had a stronger impact on children's perceptions about a food's fruit content than a fruit name alone. Perhaps children recognize the fruit visually, but are less familiar with fruit-related terms (i.e. juicy or specific fruit names), or have limited reading skills thereby making the text on labels less meaningful. Additionally, the images were constantly visible while the child was viewing a label photograph, whereas the verbal terms were spoken less often. Results also suggest that the effect of a fruit image is enhanced by a fruit name.

A comparison of the accuracy rate for identifying real fruit foods across conditions suggests that children are less accurate using food labels than advertisements. However, this difference may be due to the differences in the nature of the conditions (static $v$. action-oriented images and different participants for food label $v$. food advertisement) and because most advertisements for real fruit foods, despite extensive searching, were for fruit juice. Given the relatively high levels of intake of fruit juice by children ${ }^{(39)}$, it is not surprising that they could correctly identify this product as containing real fruit. However, they were equally incorrect in their identification of colourful 'sham' fruit drinks as containing real fruit. Thus, it appears that children perceive colourful beverages as containing fruit whether or not they do.

Misleading labels and advertisements may prevent children from making informed decisions and being able to identify healthier food options and may partly explain why fruit intake remains lower than recommended, while intake of sham fruit foods and drinks continues to rise ${ }^{(40,41)}$. It appears that improved enforcement of existing statutes and regulations governing misleading packaged labels is needed.

In the USA, the Food and Drug Administration, the US Department of Agriculture and the Federal Trade Commission share responsibility for enforcing laws designed to protect consumers from deceptive claims about foods ${ }^{(21)}$. The Federal Trade Commission has statutory authority to enforce laws prohibiting deceptive or unfair advertising and, with regard to food, laws prohibiting false or misleading advertisements ${ }^{(21)}$. A deceptive or unfair advertisement includes or omits information about a product, including its health benefits, that is likely to mislead consumers $^{(21)}$. For instance, the Federal Trade Commission ruled that an advertisement was deceptive because it claimed an ice cream bar was ' $99 \%$ fat free' because the claim applied only to the ice cream and did not include the chocolate coating (which was $40 \%$ fat $)^{(42)}$. An advertisement claiming that a low-fat soup was 'heart healthy' was deemed misleading because it did not disclose the soup's high sodium content ${ }^{(42)}$. An advertisement for processed cheese slices was ruled deceptive based on a misleading visual depiction that falsely implied each slice had more calcium than it actually $\operatorname{did}^{(43)}$.

The Food and Drug Administration has the primary responsibility for regulating food labels. It enforces the Federal Food, Drug, and Cosmetic Act (FDCA) which prohibits false or misleading labelling of foods and drinks ${ }^{(21,44)}$. Food labelling includes textual information, such as the product name, weight, manufacturer name and address, nutrition facts label, ingredient list, and health and nutrient content claims, as well as images (e.g. drawings, photographs) ${ }^{(45,46)}$. Labelling regulations pertinent to the study reported here are those that focus on misleading product names and images. Regulations require a food's name to accurately identify or describe its basic nature or characterizing properties or ingredients. The food's package should include the percentage of characterizing ingredients when their proportion in a food has a material bearing on price or consumer acceptance, or if the label or food's appearance may create an erroneous impression that certain ingredients are present in amounts greater than actually present ${ }^{(46,47)}$. Artwork on food labels is restricted only to the extent that it cannot hide or detract from the prominence and visibility of required label textual information or misrepresent the food ${ }^{(45,46)}$. Beverage labels that imply they contain juice by using pictures of fruits are required to have a percentage juice declaration $^{(45,46)}$. 
The Lanham Act, which governs trademark law in the USA, provides further protection against false or misleading descriptions of product qualities and characteristics on packing, advertising or product promotion ${ }^{(48)}$. This Act was recently used to successfully prevent a company calling a food containing less than $1 \%$ pomegranate juice as 'Pomegranate-Blueberry ${ }^{\text {(15), }}$, despite the plaintiff's arguments that Food and Drug Administration regulations allow foods to be named by their minority contents. US Supreme Court Justice Anthony Kennedy opined that 'the FDCA and Lanham Act complement each other in the federal regulation of misleading labels. Congress did not intend the FDCA to preclude Lanham Act suits ${ }^{\text {(15) }}$. This new ruling could lead to more accurate food and beverage labelling and advertising ${ }^{(16)}$.

The present study is among the first to investigate how food label and advertisement elements affect children's perceptions about food content. Important study strengths include controlling for familiarity of all real fruit and sham fruit product labels and advertisements; unanimous agreement among a panel of researchers that the selected real fruit and sham fruit food package labels and advertisements met the criteria set for each element variation; and presentation of food labels and advertisements in a random sequence for every participant to prevent primacy and recency effects. The practice session that was conducted with each participant at the beginning of data collection helped to ensure children were cognitively mature enough to participate in the study. A further strength was that all data collectors were trained and followed a written protocol in order to ensure that the study was conducted with fidelity during each data collection session. Results must also be considered in light of study limitations. The study sample was limited to a single geographic region of the USA and, thus, may not be reflective of those living elsewhere. Also, a limited variety of advertisements for real fruit foods could be located.

The study indicates that labels and advertisements for sham fruit foods mislead children with regard to the foods' real fruit content. Only one other study similar to the one reported herein could be found and it was conducted three decades ago ${ }^{(18)}$. Both the present study and the older study found that children were deceived about the real fruit content of foods advertised on television ${ }^{(18)}$. This suggests that the use of fruit words and images to label and advertise sham fruit foods may be misleading children about the foods' true fruit content. This also may affect children's ability to make informed food choices and consume enough real fruit, especially those who are cognitively younger. Due to these implications, greater enforcement of existing statutes and regulations is needed to ensure that food packaging and advertisements do not deceive consumers. Future research should seek to determine whether advertising, food name or packaging images affect product choice and product use $\mathrm{e}^{(21,22)}$ and extrapolate the potential cost of these behaviours on health and longevity.

\section{Acknowledgements}

Acknowledgements: The authors thank the children and their parents for agreeing to participate in this study. Financial support: This research received no specific grant from any funding agency in the public, commercial or notfor-profit sectors. Conflict of interest: None. Authorship: The draft of the paper was conceptualized and written by R.H., J.M.-B. and C.B.-B. A.B.-G. helped to collect data with R.H. and J.M.-B., and V.Q. helped with analysing data. All authors have read and approved this final draft. Ethics of human subject participation: Permission to conduct this study was secured from the authors' university Institutional Review Board prior to recruitment.

\section{References}

1. Byrd-Bredbenner C \& Grasso D (2000) What is television trying to make children swallow? Content analysis of the nutrition information in prime-time advertisements. $J$ Nutr Educ 32, 187-195.

2. Batada A, Seitz M, Wootan M et al. (2008) Nine out of 10 food advertisements shown during Saturday morning children's television programming are for foods high in fat, sodium, or added sugars, or low in nutrients. J Am Diet Assoc 108, 673-678.

3. Harrison K \& Marske A (2005) Nutritional content of foods advertised during the television programs children watch most. Am J Public Health 95, 1568-1574.

4. Powell L, Szczypka G, Chaloupka F et al. (2007) Nutritional content of television food advertisements seen by children and adolescents in the United States. Pediatrics 120, 576-583.

5. Byrd-Bredbenner C (2002) Saturday morning children's television advertising: a longitudinal analysis. Fam Consum Sci Res J 30, 382-403.

6. Byrd-Bredbenner C, Quick V \& Grenci A (2010) Effect of a television programme on nutrition cognitions and intended behaviours. Nutr Diet 67, 143-149.

7. Federal Trade Commission (1967) Fair Packaging and Labeling Act, Title 15 - Commerce and Trade. Chapter 39 - Fair Packaging and Labeling Program. Washington, DC: FTC.

8. Silverglade B \& Heller I (2010) Food Labeling Chaos: The Case for Reform. Washington, DC: Center for Science in the Public Interest.

9. Underwood R, Klein N \& Burke R (2001) Packaging communication: attentional effects of product imagery. $J$ Prod Brand Manage 10, 1-19.

10. Underwood R \& Klein N (2002) Packaging as brand communication: effects of product pictures on consumer responses to the package and brand. $J$ Market Theor Pract 10, 58-68.

11. Homer P \& Gauntt S (1992) The role of imagery in the processing of visual and verbal package information. J Mental Image 16, 123-144.

12. MacInnis D \& Price L (1987) The role of imagery in information processing: review and extensions. J Consum Res 13, 473-491.

13. Horovitz B (2007) Food marketers go on a berry fruity-licious kick. USA Today, 9 July; available at http://usatoday30.usa today.com/money/industries/food/2007-07-08-fruit-products_ N.htm

14. Underwood R \& Ozanne $\mathrm{J}$ (1998) Is your package an effective communicator? A normative framework for increasing the communicative competence of packaging. J Market Commun 4, 207-220. 
15. Reporter of Decisions (2014) Syllabus Pom Wonderful LLC v. Coca-Cola Co. Washington, DC: Supreme Court of the United States.

16. Horovitz B (2014) New ingredient in food labels may be honesty. USA Today, 12 June; available at http://www.usa today.com/story/money/business/2014/06/12/food-labelspom-wonderful-coca-cola-supreme-court/10381115/

17. Chandon P \& Wansink B (2007) The biasing health halos of fast-food restaurant health claims: lower calorie estimates and higher side-dish consumption intentions. J Consum Res 31, 301-314.

18. Ross R, Campbell T, Huston-Stein A et al. (1981) Nutritional misinformation of children: a developmental and experimental analysis of the effects of televised food commercials. J Appl Dev Psychol 1, 329-347.

19. Finnegan J \& Viswanath K editors (2008) Communication Theory and Health Behavior Change: The Media Studies Framework, 4th ed. San Francisco, CA: Jossey-Bass.

20. Habermas J (1984) Theory of Communicative Action. Boston, MA: Beacon Press.

21. Federal Trade Commission (1994) Enforcement Policy Statement on Food Advertising. Washington, DC: FTC.

22. Shabbir H \& Thwaites D (2007) The use of humor to mask deceptive advertising. $J$ Advert 36, 75-85.

23. Borzekowski D \& Robinson T (2001) The 30-second effect: an experiment revealing the impact of television commercials on food preferences of preschoolers. J Am Diet Assoc 101, $42-46$.

24. Donohue T, Meyer T \& Henke L (1978) Black and White children: perceptions of TV commercials. J Market 42, 34-40.

25. Lewis M \& Hill A (1998) Food advertising on British children's television: a content analysis and experimental study with nine-year olds. Int J Obes Relat Metab Disord 22, 206-214.

26. Signorielli N \& Lears M (1992) Television and children's conceptions of nutrition: unhealthy messages. Health Commun 4, 245-257.

27. Signorielli N \& Staples J (1997) Television and children's conceptions of nutrition. Health Commun 9, 289-301.

28. Roberto C, Baik J, Harris J et al. (2010) Influence of licensed characters on children's taste and snack preferences. Pediatrics 126, 88-93.

29. Robinson T, Borzekowski D, Matheson D et al. (2007) Effects of fast food branding on young children's taste preferences. Arch Pediatric Adolesc Med 161, 792-797.

30. Van Evra J (1995) Advertising's impact on children as a function of viewing purpose. Psychol Market 12, 423-432.

31. Mintel International Group Ltd (2010) Family Purchases: Kids as Influencers - US. Chicago, IL: Mintel International Group Ltd.

32. Galst J \& White M (1976) The unhealthy persuader: the reinforcing value of television and children's purchase-influence attempts at the supermarket. Child Dev 47, 1089-1094.
33. Hitchings E \& Moynihan P (1998) The relationship between television food advertisements recalled and actual foods consumed by children. J Hum Nutr Diet 11, 511-517.

34. Cohen D, Scribner R \& Farley T (2000) A structural model of health behavior: a pragmatic approach to explain and influence health behaviors at the population level. Prev Med 30, 146-154.

35. Kunkel D, McKinley C \& Wright P (2009) The Impact of Industry Self-Regulation on the Nutritional Quality of Foods Advertised on Television to Children. Oakland, CA: Children Now.

36. Valkenburg P (2004) Children's Responses to the Screen: A Media Psychological Approach. Mahwah, NJ: Erlbaum.

37. Young B (2000) Children's categorisation of food. Int J Market 19, 495-508.

38. Bahn K (1986) How and when do brand perceptions and preferences first form? A cognitive developmental investigation. J Consum Res 13, 382-393.

39. Nicklas T, O'Neil C \& Kleinman R (2008) Association between $100 \%$ juice consumption and nutrient intake and weight of children aged 2 to 11 years. Arch Pediatr Adolesc Med 162, 557-565.

40. Park S, Pan L, Sherry B et al. (2014) Consumption of sugarsweetened beverages among US adults in 6 states: behavioral risk factor surveillance system, 2011. Prev Chronic Dis 11, 130304 .

41. Grimm K, Blanck H, Scanlon K et al. (2010) State-specific trends in fruit and vegetable consumption among adults United States, 2000-2009. MMWR 59, 1125-1130.

42. Gilcrest L (2003) Food ads recently nabbed by FTC discussed at FDLI meeting. Food Chem News 45, 24.

43. Campbell A (2010) Identifying and Reporting Misleading Ads. How to Help Enforce Federal Regulations Limiting Deceptive or Unfair Marketing. Oakland, CA: National Policy \& Legal Analysis Network to Prevent Childhood Obesity.

44. US Congress (1938) Federal Food, Drug, and Cosmetic Act, Public Law No. 79-489, Stat. 427.

45. US Food and Drug Administration (2008) Food Labeling Guide, Guidance for Industry, A Food Labeling Guide. Washington, DC: FDA; available at http://www.fda.gov/ downloads/Food/GuidanceRegulation/UCM265446.pdf

46. US Food and Drug Administration (2013) Guidance for Industry: A Food Labeling Guide (4. Name of Food). Washington, DC: FDA; available at http://www.fda.gov/ Food/GuidanceRegulation/GuidanceDocumentsRegulatory Information/LabelingNutrition/ucm064872.htm

47. US Congress (1977) 21 C.F.R. § 102.5, Title 21: Food and Drugs, PART 102-Common Or Usual Name For Nonstandardized Foods, 21 U.S.C. 321, 343, 371, 42 FR 14322.

48. US Congress (1946) Lanham Act, Public Law No. 79-489, Stat. 427. 